Casos Clínicos

Arch. Esp. Urol. 2010; 63 (5): 396-400

\title{
PSEUDOTUMOR TESTICULAR POR "CORYNERBACTERIUM THOMMSENII"
}

Ignacio Gómez García, Enrique Gómez Mampaso', Marta Romero Molina² y Antonio Gómez Rodríguez.

Servicio de Urología Hospital Virgen de la Salud. Toledo. 'Servicio de Microbiología. Hospital Ramón y Cajal. Madrid.

${ }^{2}$ Servicio de Nefrología Hospital Virgen de la Salud Toledo. España.

Resumen.- OBJETIVO: Informamos del primer caso descrito en la literatura de infección genitourinaria por Corynebacterium Thomssenii en el hombre.

MÉTODOS: Estudio descriptivo de infección testicular por germen atípico y desconocido en un paciente, siendo identificado y diagnosticado gracias a la Reacción en Cadena de la Polimerasa (PCR), realizamos búsqueda en la bibliografía universal de casos similares.

Ignacio Gómez García

Servicio de Urología

Hospital Virgen de la Salud

Avda. de Barber, s/n

45004 Toledo (España)

naggoga@yahoo.es

Aceptado para publicar: 15 de diciembre 2009 
RESULTADOS: Encontramos solo un caso de infección pleural por Corynebacterium Thomssenii en el hombre, no estando descritos ningún caso de afección genitourinaria.

CONCLUSIONES: Hasta el momento actual no existen más que un caso descrito de infección por $C$. Thomssenii en el hombre, posiblemente debido a infradiagnostico, por el lento crecimiento de este patógeno. Los métodos de amplificación genética mediante PCR deben ser más demandados por el clínico ya que aportan un adelanto en el diagnóstico microbiológico en patógenos de lento crecimiento.

Palabras clave: Pseudotumor testicular. Thomssenii. Corynebacterium.

Summary.- OBJECTIVE: To report the first case described of genitourinary infection by Corynebacterium Thommsenii in a man.

METHODS: Descriptive study of a testicular infection by an atypical unknown germ in a patient, which was identified and diagnosed thank to the use of Polymerase chain reaction (PCR). We performed a bibliographic search of similar cases.

RESULTS: We only found one case of pleural infection by Corynebacterium Thommsenii in the human being, with no case of genitourinary involvement described.

CONCLUSIONS: To date there is only one case described of infection by Corynebacterium Thommsenii in human beings, possibly due to underdiagnosis for the slow grow of this pathogen. Genetic amplification methods by PCR should be demanded more frequently by clinicians because they provide an advance in the microbiologic diagnosis is slow-growing pathogens

Keywords: Testicular pseudotumor. Thommsenii. Corynebacterium.

\section{INTRODUCCIÓN}

Presentamos el Primer caso descrito en la literatura de infección genitourinaria por Corynebacterium Thomssenii, y el segundo de infección por esta bacteria en el hombre.

El corynebacterium Tomssenii fue descrito por primera vez por Zimmermann et al en 1998 (1), en una muestra de tejido pleural; desde entonces hasta el momento actual no se ha descrito ningún otro caso de infección por este patógeno en el hombre.

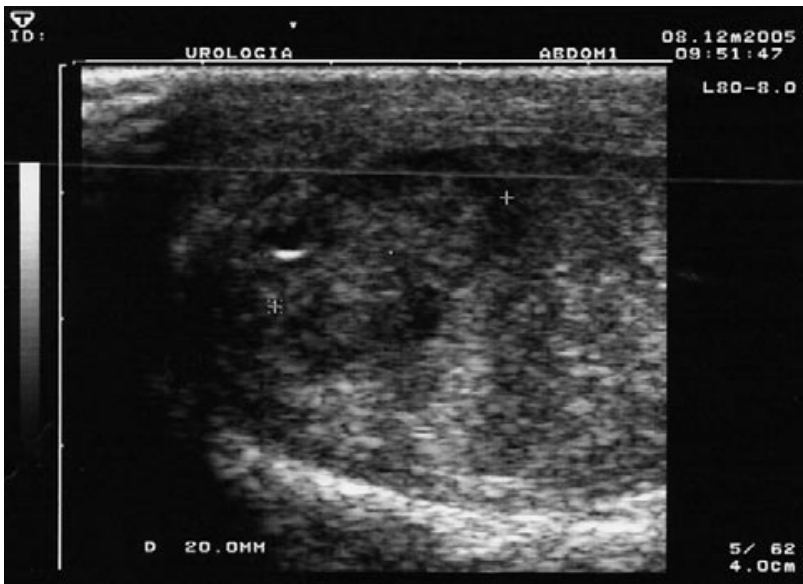

FIGURA 1. Ecografía Testicular: Tumoración testicular hiperecogénica.

\section{CASO CLÍNICO}

Varón de 48 años natural de Argentina sin antecedentes personales de interés con aumento y dolor progresivo del testículo izquierdo de 2 meses de evolución; no refiere sintomatología urinaria, no fiebre. Tratado con distintas pautas antibióticas sin mejoría.

En la exploración física, se aprecia tumoración dura en teste izquierdo no dolorosa y sin signos de fluctuación. Pruebas complementarias: Hemograma: Destaca linfocitosis, resto normal. Sedimento de orina: Piuria. Cultivo de orina: estéril. Cultivos de semen: E. coli (1\%),S. Sprophiticus $\left(2^{\circ}\right)$, P.Mirabilis(3). Marcadores tumorales: CEA, alfa feto y BHCG normales. Ecografía urinaria: normal. Ecografía testicular (Figura 1): Tumoración testicular izquierda heterogénea sin áreas liquidas en su

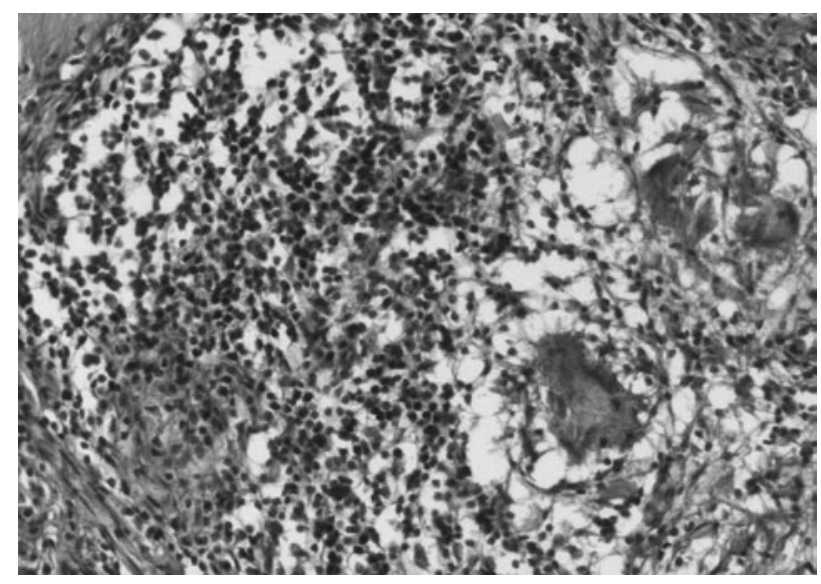

FIGURA 2. Estudio Patológico: Inflamación granulomatosa no caseificante con histiocitos vagamente epitelioides y células gigantes tipo Langhans. Perifericamente se observa corona linfocitaria. 
interior. Mantoux positivo con ulceracion. Ante la ausencia de mejoría clínico radiológica se realiza orquiectomía radical siendo informado el estudio patológico de orquitis inespecífica (Figuras 2 y 3 ).

Se remite muestra a microbiología, constituida por exudado purulento obtenido intraoperatoriamente del tejido testicular. La tinción de auramina para micobacterias fue negativa. En la tinción de Gram se observaron leucocitos polimorfonucleares y escasos bacilos $\operatorname{Gram}(+)$, alguno de ellos filamentosos, con tinción irregular y con extremos bacilares abultados en forma de mazas. La amplificación genómica (PCR) para M.tuberculosis fue negativa. La detección del antígeno de Chlamydia fue también negativa. El cultivo para bacterias habituales, incluidas Neiserias y Haemophilus, fueron negativos a las 72 horas de incubación.

A las 96 horas, se detectó en el cultivo el crecimiento (Figuras 4 y 5), de un microorganismo muy adherente al medio, difícil de emulsionar que a la tinción de Gram presentaba una morfología de bacilo $\operatorname{Gram}(+)$ de aspecto coryneforme, a veces con tinción irregular y algunos con terminaciones en forma de maza La tinción de Ziehl Neelsen modificada fue negativa.

La identificación fenotípica no aportaba datos significativos por los que se procedió al estudio genético mediante secuenciación del 16SrRNA, identificándose la cepa como Corynebacterium thomsseni. Los cultivos para Nocardias, Micobacterias y hongos fueron negativos. La cepa aislada era muy sensible a Penicilina, Ampicilina,Amoxicilina con clavulánico, Cefotaxima, Gentamicina, Amikacina, Eritromicina,Tetraciclina, Trimetroprim sullfametoxazol, Rifampicina e Imipenem.

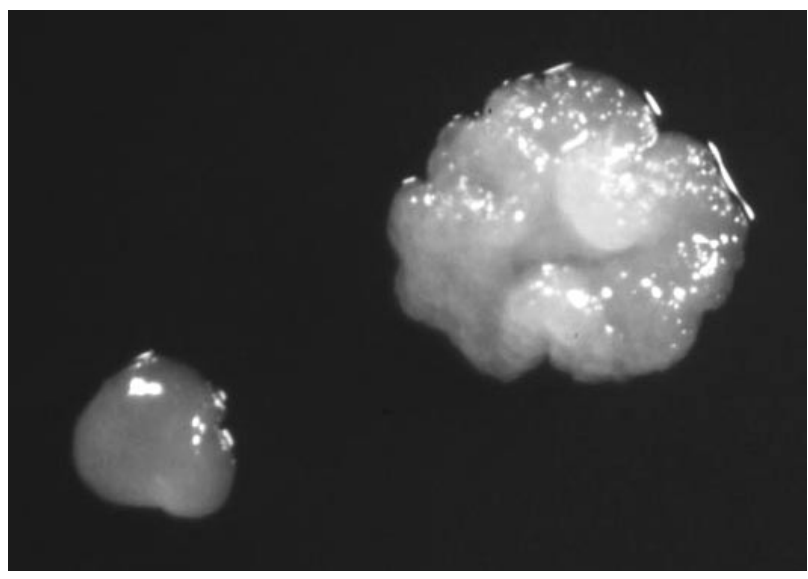

FIGURA 3. Colonia de CorynebacteriumThomssenii en agar sangre a los tres días e incubación, a 12 aumentos.

\section{DISCUSIÓN}

Los pseudotumores testiculares se definen como procesos intratesticulares expansivos de causa no tumoral, la etiología es diversa; siendo las orquioepididimitis por gérmenes típicos y atípicos (micobacterias, nocardia, corynebacterium, blastomicosys $2,3,4$ ) la causa mas frecuente; otras causas menos habituales son las parasitosis, orquitis xantogranulomatosa, isquemia testicular... Cada vez hay que pensar más en estos gérmenes atípicos dada la proliferación de pacientes que están sometidos a terapia inmunosupresora por cualquier causa, o bien en pacientes con déficit del sistema inmunitario por enfermedades sistémicas (9).

Las orquioepidimitis (OE) infecciosas dependiendo de la edad y tendencia sexual, pueden ser producidos por diversos microorganismos. Las infecciones testiculares en niños son infrecuentes, de etiología no clara y suele subyacer alteraciones anatómicas. Otras causas menos frecuentes de $\mathrm{OE}$ en el niño: bacteriemias por $\mathrm{h}$. Influenzae, tras infección del aparato respiratorio, Salmonella, púrpura de Schonlein Henoch, Paramyxovirus... En varones con edad inferior a 35 años la orquioepidimitis usualmente se encuentra asociados a con organismos de transmisión sexual como Chlamidya trachomatis, o Neisseria gonorrhoeae; en varones heterosexuales de edad mas avanzada las infecciones suelen asociarse a patógenos entéricos como, eschericha, proteus, pseudomonas, Streptoccocci, mientras que en varones homosexuales los patógenos pueden ser tanto entericos como de transmisión sexual. En varones por encima de los 50 años la etiología mas frecuente es el cateterismo vesical o estudios diagnósticos invasivos; otros factores predisponentes: alteraciones anatómicas (hiperplasia benigna de próstata, estenosis uretra, litiasis...), inmunosupresión, portador permanente de sonda vesical, pacientes oncológicos.

El genero Corynebacterium fue definido en 1896 por Lehman y Neuman, siendo la C. diphterie la bacteria tipo en este género; denominandose bacterias difteroides o coryneformes a las bacterias con morfología similar. Las bacterias differoides engloban a un grupo que incluyen los géneros Corynebacterium, arcanobacterium, Brevibacterium, Dermabacter, Microbacterium, Rothia, Turicella, Arthrobacter y Oerskovia.

Las Corynebacterias son saprofitos de plantas, membranas y mucosas de humanos y animales, encontrándose también en material e instrumental medico. Este género causa con mayor frecuencia infecciones en animales $y$ raramente en el hombre sano. Se han descrito infecciones por este grupo en enfermos inmunodeprimidos. En los últimos años ha existido un aumento del número de descripciones de especies del genero corynebacteryum. Este género esta compuesto por más de 35 especies. 
El aumento de pacientes inmunodeprimidos, con enfermedades crónicas, ha producido un aumento de infecciones por corynebacterias como patógeno oportunista (1). El espectro de infecciones producidas por las bacterias coryneformes se pueden dividir en dos categorías: infecciones adquiridas en la comunidad e infecciones nosocomiales. Las infecciones adquiridas en la comunidad más frecuentes son faringitis, infecciones genitourinarias, e infecciones periodontales; las infecciones nosocomiales son menos frecuentes, siendo usuales en enfermos graves, inmunodeprimidos o en aquellos portadores de catéteres y material protésico (6); los gérmenes nosocomiales más frecuentes son $C$. Jeikeium, $C$. Urealyticum, C. Amycolataum y C. Striatum. Se prevé un aumento de infecciones nosocomiales por gérmenes coryneformes debido al aumento de pacientes graves, al elevado índice de estancia en unidades de cuidados intensivos, y a la administración de terapia polimicrobiana.

En la literatura revisada solo se ha encontrado casos de infección urinaria en forma de uretritis, cistitis y pielitis incrustante y bacteriemia asintomática por $C$. urealyticum (7), no encontrando referencia a infección genitourinaria por $\mathrm{C}$. Thomsenii; siendo el presente caso el primer caso descrito de infección genital por corynebacterias y en particular por C.thomsenii y el segundo caso de infección de este patógeno en el hombre (1).

La tinción de Gram es característica la formación de "barras" de bacterias gram positivas, aunque existen corynebacterias que no presentan formación en "barras". Las bacterias coryneformes son bacterias pleomórficas, pudiendo aparecer en distintas formas según su ciclo vital (desde cocos hasta bacilos); siendo característica la agrupación en forma de "letras chinas", y la ausencia de formación de esporas.

La contaminación de los cultivos por corynebacterias, y la aparición frecuente en cultivos de infecciones polimicrobianas, requiere la aplicación de criterios estrictos para la determinación de la corynebacteria como agente etiológico de la infección (2):

- Obtención de la muestra de un medio estéril

- Elevado numero de bacterias en la tinción de Gram,

- Obtención en cultivo puro.

La extensión en medios de cultivos de agar sangre se objetiva un crecimiento lento de colonias, opacas blancas o grises, con ausencia de hemolisis similar a la producida por los Streptococcos alfa hemolíticos. La mayoría de los patógenos urinarios tiene un crecimiento rápido aislándose en 24 horas; siendo el $C$. Urealyticum una excepción con una incubación superior a las 48 horas, siendo necesario el creci- miento en un medio selectivo. La determinación de los distintos grupos de corynebactias viene determinado por pruebas bioquímicas: test de catalasa, reducción de nitratos, producción de urea, hidrólisis de distintas sustancias( sacarosa, glucosa, maltosa, manitol....); el sistema API CORYNE incluye 20 test bioquímicos que identifica el $90,5 \%$ de las corynebacterias mas habituales; otros sistemas de identificación también utilizados son el sistema RapID CB, y el sistema CAMP $(2,8)$. Los estudios por biología molecular mediante la sustracción 16SrDNA de la muestra, con amplificación posterior por PCR confirma la identificación de la especie $(2,10)$.

Ante al ausencia de resolución de una OE es importante excluir procesos testiculares malignos, siendo necesario el estudio ecográfico y en ocasiones la exploración quirúrgica (4). La distinción entre orquitis, y otras patologías puede ser dificultosa mediante la ecografía, siendo complicado ya que el $10 \%$ de los tumores malignos refieren historia de infección (3), la asociación con doppler aumenta la certeza diagnostica en un $29 \%$ (4); la heterogenicidad ecográfica en las $\mathrm{OE}$ es la norma, abarcando desde áreas parcheadas hipoecogénicas, hiperrefringencia septal, aumento ecogenicidad de la rete testis, colecciones liquidas...(3). La RMN en los que no existe mejoría a las 4 semanas puede aportar una mejora en la aproximación diagnostica (14). La RMN se ha demostrado útil en el diagnóstico de pseudotumores fibrosos sobre todo en T2, y en T1 postcontraste (5).

Cuando las pruebas de imagen no son capaces de discernir entre procesos benignos o malignos, los datos microbiológicos son inciertos, la orquiectomía radical es manadatoria (5). La indicación quirúrgica principal es la incertidumbre diagnóstica; otras indicaciones son: recurrencia de episodios, ausencia de respuesta al tratamiento, abcesificación $(3,4)$. Actualmente la orquiectomía es aceptada tras ausencia de mejoría clínica y radiológica tras 3-4 semanas de seguimiento y tratamiento (5).

\section{CONCLUSIONES}

Las lesiones pseudotumoreales son frecuentes en procesos infecciosos refractarias al tratamiento, la presencia de las mismas nos debe hacer sospechar de infecciones genitales por bacterias atípicas y en patología tumoral. La persistencia de la sintomatología y de los hallazgos ecográficos, el ecografía doppler y la RMN pueden orientar hacia el diagnostico, debiendo realizar orquiectomía radical ante la duda diagnóstica.

La determinación por primera vez e C. Thommsenii en el testículo, es un hecho fortuito ya que probablemente la infección por este patogeno sea mas frecuente, existiendo en realidad un infradiagnostico microbiológico, 
por el lento crecimiento de este patógeno y sus características bioquímicas y morfológicas. Los métodos de amplificación genética mediante PCR den ser mas demandados por el clínico ya que aportan un adelanto en el diagnóstico microbiologicos en patógenos de lento crecimiento.

\section{BIBLIOGRAFÍA Y LECTURAS RECOMENDADAS ( ${ }^{*}$ lectura de interés y lectura fundamental)}

**1. Zimmermann O, Spröer C, Reiner M et al. Corynebacterium thomsenii sp. Nov., a corynebacterium with $\mathrm{N}$-acetyl- B- glucosaminidase activity from human clinical specimens. International Journal of System Bacteriol,. 1998; 48. 489-94.

2. Funke G, von Graevenitz A, Clarridge J. Clinical microbiology of coryneform bacteria. Clin Microbiol Rev, 1997; 10. 125-29.

**3. Hagley M. Epididymo orchitis and epidymitis: a review of causes and management of unusual forms. Int Jour of STD\&AIDS, 2003; 372-7.

*4. Manish G, Hanelin L. Seminoma mimicking epididymorchitis as scrotal swelling on scrotal scintigraphy. Clin Nuc Med, 1999; 10 803-4.
**5. Krainik A, Sarrazin JL, Camparo P, et al. Fibrous pseudotumor of the epididymis: imaging and pathologic correlation. Eur radiol, 2000; 10: 1636-8.

6. Kuriyama T, Karasawa T, Nakagawa K. Bacteriology and antimicobial susceptibility of gram positive cocciisolated from pusspecimenes of orofacial odontogenicinfections. Orsl Microbiol Immunol, 2002; 17;132-5.

*7. Remacha Esteras MA, Guerra Laso JM, Esteban Martin A, et al. Infección urinaria por corynebacterium urealyticum. Actas Urol Esp, 2004; 28:75-6.

8. Funke G, Peters K, Aravena Romman M. Evaluation of the RapiD Cb plus systemfor identification of coryneform bacteria in Listeria spp. J. Clin Microbiol, 1998; 36: 2439-42.

9. Vesa J, Bielsa O, Arango O, Llado C, Gelabert-Mas A. Massive renal Infarction due to Mucomycosis in an AIDS patient. Infection, 1992; 20, 4: 234-6.

10. Tang Y, von Graevenitz A, Waddington M, et al. Identification of coryneform bacterial isolated by ribosomal DNA sequence analysis. J Clin Microbiol, 2000, 38: 1676-8. 